dt the Sedan French Ambulance, situated in what had been a large cloth warehouse, there had been three cases of primary amputation at the hip-joint; one of which was doing well twenty-four days after injury. One officer, who had both legs and both arms amputated at this hospital, was making a good recovery. A cavalry officer, he was riding when a ball struck both his legs, passing through and killing his horse; and a second bullet went through both his arms. The amputations were said to have been performed in spite of the patient's earnest entreaties to be left to die.

The Swiss Ambulance in Sedan had been a cotton mill, of which the three upper stories were occupied, the groundfloor being used for stores, \&c. The windows were so numerous that there was almost one to each bed. The rooms were low, but very freely ventilated by means of the windows and the cracks in the floors. Free living, rest, and carbolic acid were the principal means employed, and with great success. Of thirty-five to forty cases of amputation, only one died. Of the cases of resection and compound fracture, none succumbed who outlived the first few days. Many were brought in dying, some even dead.

We must not quit the subject of Sedan without noticing the very unsavoury state of the river Meuse, in which large numbers of horses and men were drowned, and which must surely ere long, as it has, indeed, to some extent already, give rise to grave results among the population.

One word as to Bazeilles-that village of the dead, as it might well be called. Once a flourishing suburb of Sedan, with a population of about 3000 , it is now as complete a ruin as the mind can possibly conceive; and the wreck of once charming villas and lively streets has become, it is to be feared, a vast mausoleum. The ambulances under the care of Dr. Frank and Dr. Woodham Weib are situated near to this place, but we had not an opportunity of seeing them. The latter is at Balan, and we have already alluded to the unfavourable condition of its inmates in speaking of the patients removed from Sedan. The history of Bazeilles and Balan alone would fill a volume; but we must pass on to our next hospital visitation.

( $T$ o be continued.)

\section{ON THE FORCE OF THE HUMAN HEART}

\section{BY ANDREW BUCHANAN, M.D.,} PRORESSOR OF PHYSIOLOGY IN THE ENIVERSITY OF GLASGOW.

As the force of the human heart is a subject that can never lose its interest to physiologists, I desire to submit the following observations upon it, suggested by an estimate of it recently made by the Rev. Dr. Haughton, of which an account is contained in the Dublin Quarterly Journal of Medical Science, vol. xlix., p. 47, under the title "On the Mechanical Work done by the Human Heart." I merely premise that $I$ wish to speak of the reverend gentleman with the most perfect respect, and that $I$ am not the less indebted to him for his testimony on behalf of my opinions that it has been unintentionally and, indeed, unconsciously given.

I shall first endeavour to show that the solution of the problem of the heart's action proposed by Dr. Haughton is, so far as it goes, essentially the same as that which I laid before the profession nearly two years ago. I shall next endeavour to show that Dr. Haughton's solution, although capable of determining the mechanical equivalent of the work done by the heart, cannot be employed to determine more minutely the work which the heart actually performs, and gives us erroneous ideas when we attempt so to employ it.

Let it, in the first instance, be taken for granted that there is no error in the data on which our respective computations are based, so that we may have nothing to consider but the use which is made of them.

The three elements which Dr. Haughton assumes as the groundwork of his computation are, that the heart contracts $7_{5}$ times in a minute; that at each contraction the left ventricle of the heart discharges three ounces of blood; and that the hæmastatic column in man stands at a height of 9.923 feet. He now multiplies the quantity of blood discharged at each contraction by the height of the hæmastatic column $(3 \times 9.923=29 \cdot 769)$, and regards the product as indicating the number of ounces that are raised one foot by each contraction of the heart. He again multiplies the product by the number of contractions of the heart in 24 hours, and so he obtains $89 \cdot 706$ foot tons as the measure of the daily work done by the left rentricle of the heart.

In addition to Dr. Haughton's three elements, I avail myself of a fourth-viz., the area of the ventricular orifice of the aorta, which I estimate with Kiel as equal to $\cdot 4187$ of a square inch, and which I regard as an element of the very highest importance in the solution of the problem of the heart's action, and the more so that it can be determined with ease, and is therefore more worthy of reliance than are some of the other elements.

Supposing, then, that we add the element just mentioned to Dr. Haughton's other three, the following is the mode in which I employ these elements to determine the force of the heart. The weight of a cylinder of blood 9.923 feet in height, and having a base of $\mathbf{4 1 8 7}$ of an inch, is $30^{\circ} 20838$ ounces. Three ounces of blood, which the heart discharges at each contraction, fill of such a cylinder 11.8245 inches, or $\cdot 985375$ of a foot. Now, multiplying together the two numbers thus found, I obtain a product of $29 \cdot 769$, the identical result obtained by Dr. Haughton-

$$
30 \cdot 208 \times \cdot 985375=3 \times 9 \cdot 923=29 \cdot 769 .
$$

I had therefore reason in saying that Dr. Haughton's computation is essentially the same as mine, seeing that their results are identical.

The same coincidence holds with respect to my own computation, and comes out still more strikingly owing to the greater simplicity of the numbers. I assume that the heart beats 72 times in a minute, that it discharges two ounces of blood at each contraction, and that the height of the hæmastatic column in man is 88 inches. Now the weight of a cylinder of blood 88 inches in height, and having a basis of -4187 of a square inch, is 22 ounces. Further, two ounces of blood, the quantity discharged at each contraction, fill exactly, of such a cylinder, 8 inches. Dr. Haughton's computation is $2 \times 88$, and that is exactly equivalent to my computation, $22 \times 8$; the common product being 176 , which denotes the number of ounces which are lifted one inch at each contraction, and by dividing 176 by 12 we obtain the number of ounces that are lifted one foot-viz., 14.66. Dr. Haughton's number for each contraction is more than double, 29.769 ; but, in addition, he makes the heart beat 75 times in a minute, instead of 72 times, so that his total estimate of the day's work is to mine in the proportion of $30 \cdot 774$.to 14.66 . But this difference does not depend on any difference in our modes of computation, which lead exactly to the same result, but merely on the different magnitudes assumed of the elements which form the base of the computations.

Neither are these accidental coincidences; for it is easy to show that the numbers obtained by Dr. Haughton's method are necessarily the same as those obtained by mine. For let $W$ denote the weight of a cylinder of blood having a base of 4.187 of an inch, and a height $(H)$ equal to that of the hæmastatic column, and let $h$ be the portion of that cylinder equal in volume to the blood emitted from the heart at each contraction, while $w$ denotes the weight of the same quantity of blood. Then, as the weights of any two portions of the same liquid are as their volumes, we have$w: W:: h: H$; and consequently $w H=W h$

Now Dr. Haughton's method consists in calculating $w H$, and mine consists in calculating $W h$ quantities, which are necessarily equal, so that the two methods must in all cases lead to the same result.

I have thus shown that the solution of the problem of the heart's action proposed by Dr. Haughton is, so far as it goes, essentially and necessarily the same as that which I laid before the profession nearly two years ago, and I now proceed to show that Dr. Haughton's solution, although capable of determining accurately the mechanical equivalent of the work done by the heart, cannot be employed to determine more minutely the work which the heart actually performs, and misleads us when we attempt so to employ it. 
To determine the work actually performed by the heart is a problem quite different from that of determining the mechanical equivalent of the work done. The very same effective force is required to raise one pound to a height of ten feet, as to raise ten pounds to a height of one foot, or five pounds to a height of two feet, or two pounds to a height of five feet. In all of these cases, and others innumerable if we descend to fractional numbers, the mechanical equivalent is the same, or ten-foot pounds; but the operations themselves are very different, and with respect to any organ acting in the living body, or any inanimate machine, we would not rest satisfied till we kness which was the operation it actually performed. Now $i t$ is just so with respect to the heart. There are questions in physiology, as Dr. Haughton has shown, to answer which the mechanical equivalent of the heart's action, or the total amount of its effective force, is all that we require to know. But there are other and more important questions for which that meagre knowledge is insufficient. The physiologist wishes to know, not only the amount of the effective force of the heart, but also in what precise way or ways that force is expended within the body. What is wanted will be better understood when I say that the effective force of the heart communicates to the blood its momentum, and that the momentum of the blood is expressed by $(q \times v)$ the mass of blood which is set in motion multiplied by the velocity with which it moves. Now we should at once attain our end if we could determine the respective values of $q$ and $v$. But it is just because we cannot do so directly, that we are obliged to have recourse to empirical formulæ. But such formulæ are only valuable as they agree, term to term, with the rational formula $(q \times v)$. Now Dr. Haughton's formula $(w \times H)$ and mine $(W \times h)$ cannot both agree, seeing that the terms are inverted - that which expresses the mass moved in the one, expressing the velocity in the other. We must judge, therefore, which of these formula gives the most probable view of the moving mass and velocity of the blood. Taking Dr. Haughton's data, and viewing them in the light of his own formula $(w H)$, we have 3 ounces of blood moved over 9.923 feet at each beat of the heart, or with an initial velocity of very nearly 750 feet per minute; which is manifestly a reductio ad absurdum. But if to the same data we apply the formula $(W h)$, we invert the ratio of the mass to the velocity, and find $30 \cdot 2$ ounces of blood moving over 985 of a foot at each beat of the heart, or with an initial velocity of 73.875 feet in the minute; which, though a high rate, is no longer so extravagant as to be incredible.

In conclusion, I may be allowed to say that I am still inclined to think favourably of my own more moderate estimate- that the heart at each contraction exerts a force which would be in equilibrium if counterbalanced by a weight of 22 ounces +129.28 grains. The mode in which this force is expended is most easily explained by supposing that we have a tube 88 inches in height and $\cdot 4187$ of an inch in base, that this tube is exactly filled with blood, and that at each contraction of the heart two additional ounces are forced in to it at the lower end, lifting the whole column over a space of 8 inches, and causing an equal overfiow at the top. This represents accurately the labour of the human heart, and supplies us with two numbers to express it: the one, 22 ounces, being the weight of the column of blood and the other, 8 inches, the space over which the column is lifted. The former of these numbers denotes the resistance that has to be overcome in forcing two ounces of blood into the aorta, and pushing before it the whole mass of blood in the bloodvessels; the latter, again, denotes the velocity with which the blood issues from the heart. Hultiplving these two numbers toctether, we obtain the momentum which the heart communicates to the blool-22 ounces moving with a velocity of 8 inches during the period of a pulsation, or of 10 inches per second, or 50 feet per minute. This is equivalent to 176 ounces $(22 \times 5)$ lifted one inch, or 1466 ounces lifted one foot, during the period of a pulsation; or of 659 foot-pounds in a minute, or $42 \cdot 3$ foot-tons in twenty-four hours.

P.S.- The facility with which the force of the heart, in whatever aspect ne choose to contemplate it, can be obtained from the weights and volumes of the columns of blood at $A, B, C$, which have seremlly a basis of 1187 of an inch, seems to me to show well the importance of assuming the area of the rentricular orifice of the aorta as an element in computing the force of the heart.
$A$ is the calculated hæmastatical column.

$B$ is the observed hæmastatical column.

$C$ is a column equal in volume to the capacity of the left ventricle of the heart.

$$
\begin{aligned}
& \text { Weight in Folume, as height of } \\
& A=22 \cdot 301 \\
& A=22.301 \quad \ldots \ldots 889.165797 \\
& B=22^{\circ} \quad \ldots \ldots 88^{\circ}
\end{aligned}
$$

Force of Heart.

1. Statical equivalent $=A=22 \cdot$ ounces $+129 \cdot 28$ grains.

2. Dynamical equivalent $=B \times C$, the weight of the one into the volume of the other.

$22 \times 8 \cdot\}=176$ inch ounces $=14 \frac{2}{3}$ foot ounces.

3. Nomentum of blood as emitted from heart

$=$ weight $B \times$ volume $C=22$ ounces moved over a space of 8 inches at each pulsation, or with a velocity of 10 inches per second.

Glasgow, Oct. 1870 .

ON THE

\section{SIMULATION OF HIP_JOINT DISEASE BY SUPPURATION OF THL BURSA OVER THE TROCHANTER MAJOR.}

\author{
By ROBERT MACNAB, M.D., F.R.C.S. Edir., \\ SURGEON TO THE SUFFOLK GENERAL HOSPITAL.
}

I READ with much interest Mr. Teale's paper on the above subject in THe LANCET of Oct. 9 th, and as I have just met with two instances of evidently the same disease, perhaps a brief history of the cases may be deemed worthy of record.

CASE 1.-Geo. P-, a highly strumous boy, eleven years of age, born in India, and the child of an officer in the Indian army. In March last, while playing at "see-saw" with his brothers, he was struck forcibly on the left hip by the end of the plank on which he had been riding. Next morning he complained of pain over the seat of the blow, and I was asked to see him. I found the left hip over the trochanter major slightly swollen, hot, and painful on pressure; walking also gave him pain; no constitutional disturbance. Ordered rest and fomentations. This treatment was continued for a week, with the result of lessened pain, but no change in the swelling over the trochanter, which seemed rather to have increased, extending farther down the thigh, and becoming more brawny to the touch. The groin also had become slightly swollen, and there was stiffness in the joint generally. Ordered perfect rest in the horizontal position, with the application of a succession of blisters over and around the trochanter major (the actual cautery being objected to), with the syrups of the phosphate and iodide of iron and cod-liver oil internally. This treatment was followed at the end of a month by the daily application of the compound tincture of iodine to the entire hip.

May 6th.-No good resulted from the above measures, and the case now simulated in a marked degree the first stages of morbus coxæ; the thigh being slightly flexed upon the pelvis, the knee adducted, and the limb generally emaciated, with decided simulation of lengthening. On comparing the hips, the convexity of the left is found flattened, the trochanter major of the same side being much more prominent, rounded, and lower than the right. No weight can be put upon the affected limb; in attempting to do so, pain is immediately complained of, not in the joint, but over the trochanter and upper part of the thigh. Still no pain on pressure over the head of the femur, nor on sharply striking the heel or lnee towards the hip-ioint. I strajghtened the limb under chloroform, and applied a long splint; no extension made, the splint being kept in position by placing its lower end between two upright pieces of iron fixed on a flat square board.

July 1st.-Patient's general health beginning to gire way. The splint was removed a week ago, having been applied more than six weeks. No improvement perceptible. Swelling over trochanter undiminished; simulated length- 